\title{
DEVELOPING THE READINESS FOR THE ORGANIZATIONAL ACTIVITY OF THE CADETS
}

\author{
Venelin Terziev, ${ }^{1}$ Nikolay Nichev ${ }^{2}$
}

\begin{abstract}
The tasks being solved by the military units, which are part of the Bulgarian Army, require the possession of highlevel knowledge and abilities for organizational activity from the newly promoted Logistic Officers. While performing his functional obligations, the Logistic Officer must promptly and thoroughly estimate the received task, duly organize the activity of the subordinated units and personnel and organize the collaboration with the State authorities, with the business, non-governmental and further organizations.

The research target is the professional military training of the future Logistic Officers, while the research subject is the developing of readiness for the organizational activity of the Logistic Officers in the course of their professional military training. The aim of the research is to outline the lines for improving the process of developing of readiness for the organizational activity of the Logistic Officers in the course of their professional military training. The research methods are: a theoretical analysis of the literature for military education and of the standard documents is made in the course of the research; analysis and synthesis of the scope and the contents of the basic definitions, being used in the elaboration; abstraction; conclusion and analogy.
\end{abstract}

UDC Classification: 378; DOI: http://dx.doi.org/10.12955/cbup.v5.1110

Keywords: military training, training of cadets.

\section{Introduction}

The tasks, which are solved by the military units, part of the Bulgarian Army, require from the newly promoted Logistic Officers to possess high-level knowledge and abilities for organizational activity. While performing his functional obligations, the Logistic Officer must promptly and thoroughly estimate the received task and the available forces and resources and must duly organize the activity of the subordinated units and personnel. The specific character of the organizational activity of the Logistic Officers has an effect on the organizing of collaboration with the State authorities, with the business, non-governmental and further organizations.

Despite this, in the Regulation for the state requirements for the regulated profession "Officer for a tactical grade of control" and in the qualification characteristic of the curriculum for Cadets training, it's paid insufficient attention to the questions for the training of the Cadets from the Logistic specialties for organizational activity. The education is directed towards the realization of the conception for the optimal obtaining of a wide range of competencies in the field of military science, and also knowledge of the activity of the civil, political, socio-economic structures and systems. Its' aim is to develop knowledge, abilities and moral-volitional qualities, serving as a ground for professional progress, but no strictly specialized training for obtaining of particular abilities for organizational activity is foreseen. (Ordinance on state requirements for acquiring higher education degree „bachelor” in professional fields "Military” in the specialties of the regulated profession „Officer for tactical levels of command", 2012; Training plans for education on specialty of regulated profession „Organization and management of military units at the tactical level” and military occupational qualification „Officer for tactical levels of command”).

\section{Acts of organizational activity}

In the scientific literature, there is no unambiguous definition of the term „organizational activity.” Some of the researchers consider it as an obligatory part of the professional activity of every expert. However this activity is scrutinized in two aspects: on the one hand as a basic professional activity, and in this case, the other activities of the expert are subordinated to it; and on the other hand as equal to the other professional activities, being a connection element of the solving of different professional tasks. Another part of the scientific commonwealth considers the organizational activity to be a function of the management process. The management process wouldn't be possible without the

\footnotetext{
${ }^{1}$ Venelin Krastev Terziev Professor, Dipl.Eng. Ph.D., D.Sc. (National Security), D.Sc. (Ec.); Vasil Levski National Military University, Veliko Tarnovo, Bulgaria; University of Rousse, Rousse, Bulgaria; University of Telecommunications and Post, Sofia, Bulgaria, terziev@skmat.com

${ }^{2}$ Nikolay Bonev Nichev, Colonel Assoc. Prof. Ph.D., National Military University, Veliko Tarnovo, Bulgaria, nicheff@abv.bg
} 
organizational activity, which in the management system is scrutinized as the basis of each management activity or as an independent kind of management activity.

The analysis of the functional obligations of a Logistic Officer defines the basic directions of revealed organizational activity in his professional military realization:

- Organization of the training and of the fulfillment of orders, given by the Commander of the unit for logistic support. The single Commander principle and the principle of the fulfillment of the ordered tasks in the Bulgarian Army is a specific sphere of the professional military activity, and in this sense, the Logistic Officer acts simultaneously as a direct executor and as an organizer of the order fulfillment. From the contents point of view, the organizational activity of the order fulfilment consists of: evaluation of the commanders' decision and of the ground and resulting tasks; evaluation of the required forces and resources for the execution of the task; taking a decision, tasks allocation; issuing of orders to the subordinate; organizing the work of the subordinate for the fulfillment of the given task; control of the execution of the tasks; evaluation of the carried out work and reporting to the Commander about the performance of the given task;

- Organizing the action of the subordinated units, of the military and civilian personnel during the performance of the missions and the tasks of the Bulgarian Army of all kinds of supplies: technical, food, materials, fuels and lubricants, ammunition, transport supplies, construction services, the supply of resources, etc.;

- Organizing the action of the subordinated military and civilian personnel and of the staff from other units during the fulfillment of the given by the Commander of the unit common tasks;

- Organization of the collaboration with the regional and the state authorities, with supply and manufacturing companies, with non-governmental and other organizations for conclusion of contracts for the delivery of defensive articles and for the providing of services aiming to enhance the military profession image and the patriotic education of the population and others;

- Organization of the cooperation between the personnel of the Logistic units and professionals forms the civilian sector for the performance of joint tasks;

- Organization of the professional military training of the subordinated personnel (Med, 2009a, Nichev, 2015).

A conclusion can be drawn from the carried out analysis, that the organization activity of the Logistic Officer in the military units, in comparison to the Commanders of combatant units, is more versatile and possesses a specific, which must be taken into consideration in the training process of the future Logistic Officers for the performance of their professional military activities. The specifics of the organization activities lies not only in its contents but also in its implementation.

Specific of the organization activity

First of all, the command and management of the activity of the Logistic units is awarded to the corresponding Commander of the unit, while the non-combatant officers organize the execution of his orders. Therefore, the organization activity must be aimed at the unconditional execution of the orders and instructions of the direct commanders and superiors and to be implemented strictly in conformity with the requirements of the operative laws, normative documents, methodologies, instructions and etc. In order to avoid the creation of a paradoxical situation, where the orders of the Commander could not be executed, because of the violations of the normative documents, laid down in them, the organization activity of the Logistic Officer ought to be directed towards assisting the Commander in taking a legitimate decision (Todorkov, 1998).

Secondly, the organization activity of the Logistic Officer is clearly regulated in the Decree of the military service, in the corresponding job description and in the orders and instructions, and for these reasons, it's appropriate to treat each innovation as a way of improving the activity, not as a radical change.

Third, the activity of most of the Officers from the Bulgarian Army and from the structures, which are directly subordinated to the Minister of Defense, is limited in the frames of the military community, while the organization activity of the Logistic Officers comes out of these frames. In order to allow him to perform a big part of the allocated tasks to him, the organizing activity of the non-combatant 
officers is tightly connected with the activity of the regional and state authorities, with the managers of different companies, with representatives of various organizations, etc. (Angelov, 1994).

Fourth, the organization activity of the Logistic Officer is being implemented within mixed teams consisting both of military men and civilians.

Fifth, on the basis of the contents part of the activity of the Logistic Officer, his organizing action is versatile and has to cover wide ranges, starting from food supplies, the supply of ammunition, technical maintenance, transport, infrastructural maintenance, etc.

Thus, the organization activity of the Logistic Officer comprises the joint organization of the work of many people from different spheres of the military life, the applying of special efforts for the providing of concordance and coordination of the activity of the people and the subordination of its results for the achievement of the basic aim - the logistic support of the military education activity. That's what makes the organization activity the main service activity, whereas the developing of its readiness in the future Logistic Officers becomes an important goal of the military profession training in the Vasil Levski National Military University.

\section{Developing of readiness for organizational activity}

Yury Med defines the иеьасхеяя of the Logistic Officers to perform an organizationьв activity as a professional and personal knowledge, comprising motivational, theoretical and practical components. Thereby the readiness appears to be a sub-system of the system of a higher level - preparedness for professional military activity and possesses all properties of the professional qualifications in part, which refers to the application of organization activities (Med, 2009b).

The motivational component of the readiness for organizational activity includes active positive relation to the organization activity and significant personal grounds for the implementation of the organization activity (grounds for self-assertion, for the scare of failure, for the achievement of positive results (Angelov, 1994).

The theoretical component of the readiness for organizational activity comprises the availability of required knowledge for the execution of the basic functions and developing of professional ethical standards for the implementation of organization activity. In conformity with the basic documents, which define the military professional activity of the Logistic Officer, the following belong to the knowledge, required for the performance of organization activities: organization and management of business units and teams, management psychology, pedagogy, deontology, ethics, conflictology, sociology, rhetoric, labor law, healthy and safe conditions of work, etc. The developing of ethical professional norms involves the possession of professional ethics, high moral consciousness, sense of responsibility, realized necessity of enhancement of the professional qualification regarding the questions of organization and management, ability to avoid, and, when necessary, to successfully solve various conflicts, the conscientious attitude to the functional obligations, respectful attitude to the inferiors etc. (Todorkov, 1998).

The practical component of the readiness for organizational activity shows out in the combination of abilities, which are necessary for the future Logistic Officer for the accomplishment of the organization activity of his first officer's position. The analysis of the possible appointment to first officer's position shows, that the list of the organization competences, he must possess, is versatile and each possible organization activity reflects in him. This fact gives a reason to unite these abilities into three groups, which are required to the greatest extent for the implementation of the organization activity.

These one are the communication abilities - skills, which allow the Logistic Officer to create his business, professional and personal relations, based on the mutual respect between him and his inferiors, his supreme commanders and chiefs, between him and the representatives of the state and local authorities and of the business, and other people, who are responsible for the logistic support of the military unit; analytical skills - the ability of a person to evaluate adequately his own personal competences and the skills of his inferiors to perform the given tasks, to evaluate the received tasks, to take the best possible decisions, to plan the performance of the tasks, to foresee the end results and the consequences of the taken decisions, to implement the obtained in the Vasil Levski National Military University knowledge for the enhancement of the effectiveness of the activity of the subordinate staff etc.; organization skills - the skills to allocate the obligations, to set out tasks for the subordinate staff, 
to secure the performance of the given tasks with the required resources, to organize the actions for the performance of the tasks, to render control and assistance during the execution, to stimulate the inferiors etc.

The developing of such components is carried out during the process of the professional military training of the future Logistic Officers.

The motivational component is being actively developed with the help of the setup system for education work. In the Vasil Levski National Military University all the army rituals and the whole education activity starting from the moment of entering the High School until the ritual for the awarding of the first officer rank are intended to develop in the Cadets the consciousness of the importance and of the particular significance of the chosen profession and to form a sense of national awareness and responsibility.

The theoretical component is formed actively during the learning of the management subjects of the civilian specialty and of the special military subjects. The management subjects of the civilian specialty give the fundamental organization theoretical knowledge, while the special military subjects give the chance of obtaining the knowledge of the structure, algorithm and the special features of the organization work of the Logistic Officers during the peacetime insurance and during the wartime support of the troops.

The practical component is formed during the performance of the tasks of the military training period, of the obligations of the army service and his appointment as a Commander of a Cadets Detachment or as Second-in-command of a Cadets detachment.

The analysis gives a ground to consider the „preparedness for organization activity” to be a goal and a result of the military professional training and a professional personal knowledge, where the organizational functions (motivational component), the level of its learning (theoretical component) and the ability to implement this experience in the future professional activity (practical component) find their reflection.

The developing of readiness for organizational activity in the Cadets during their professional military training is predetermined by many factors, among which a special place is occupied by the specially created for that purpose educational conditions (Med, 2009b). Here belong:

- developing of a positive attitude to the performance of the organizational activity. This is achieved with the help of developing sense of initiative, self-confidence in their own competences, responsibility, independence, inclination to reasonable taking a risk, etc. in the Cadets and of realized idea that the organization activity is an important part of the military professional management activity of the future non-combatant officers;

- Stimulate the obtaining of knowledge and professional ethical standards in the sphere of the organizational activity during the professional military training. The knowledge of organizational activity mustn't have just a general theoretical characteristic but must be connected to the appointing to the first officer position and to the performance of particular official obligations.

In order to achieve it, it's necessary to turn the attention of the Cadets during the process of learning the special military subjects to the interdependence between all components of the organizational activity in the Logistic units and to the enhancement of the confidence in their own organizational abilities.

- The focused development of the organizational activity aiming to meet the requirements of the first officer position. In this case, we must have in mind the fact, that it's impossible to obtain the full range of competencies, which would be needed by the future Logistic Officer in his organizer role. The number of these abilities is huge, and it's really exceptionally difficult for the Cadets from the Logistic profiles to obtain all of them. That's why it's most advisable to develop the relatively independent groups of abilities, which characterize the personality requirements for the future officers and to take into consideration the contents and the peculiarity of the future organization activities. The described communication, analytical and organization skills belong to such groups of competences.

\section{Conclusion}

As e result of the carried out analysis the following conclusions can be drawn: 
1. The organizational activity takes a specific place in the structure of the professional military activity of the non-combatant officers. This place is predetermined by the versatile characteristics of the contents, of the kind and peculiarity of the solved tasks during the performance of their official obligations and represents a necessary condition for a successful official activity.

2. The readiness for organizational activity comprises motivational, theoretical and practical components. The contents of these components ensure the developing of a positive attitude to the organization activity of the future non-combatant officers, obtaining the knowledge of the organization activity and development of the needed organization competencies for the execution of their functional obligations.

3. The developing of readiness for organizational activity during the professional military training of the Cadets is predetermined by many factors, among them an important place is occupied by the positive attitude to the performance of the organization activity; the stimulation of obtaining knowledge and professional-ethical norms in the sphere of the organization activity during the process of the military professional training; purposeful development of the organizational activity in order to meet the requirements of the first officer position.

\section{References}

Angelov, Z. (1994). Psychological problems warrior activities. Sofia: Publishing the Ministry of Defence „St. George”.

Med, J. D. (2009a). Formation of Readiness for Organizational Activity of the Future Logistic Officers. Saratov, Russia: Monograph. „Scientific Book”.

Med, J. D. (2009b). Pedagogical formation of readiness of the future officers to organizational activities. Classical university education for the XXI century: the accessibility, efficiency, quality // Collection scientific works (Vol. Part 2). Saratov, Russia: University Of Publishing Center "Science", 15-20.

Nichev N., P. E. (2015). Professional training of future logistics officers at national military university of Bulgaria. Sibiu, Romania: Knowledge Based Organization International Conference, „Nicolae Balcescu” Land forces academy, (21), 253257.

Ordinance on state requirements for acquiring higher education degree „, bachelor” in professional fields „, Military” in the specialties of the regulated profession „, Officer for tactical levels of command”. (04.09.2012). effective from the academic 2012-2013 year.

Todorkov, K. (1998). Psychological aspects of management of the commander. Sofia: Publishing the Ministry of Defence „St. George".

Training plans for education on specialty of regulated profession "Organization and management of military units at the tactical level" and military occupational qualification „Officer for tactical levels of command”. (n.d.). 